Баярсайхан C.Б.

\title{
Особенности трактовки саксофона в произведениях для симфонического оркестра
}

\begin{abstract}
Аннотация: Данная статья посвящена одной из важных и малоисследованных проблем инструментовки - трактовке инструментов семейства саксофонов в качестве оркестровых инструментов - и отражает основные научные выводы одноимённого диссертационного исследования. Основываясь на результатах анализа авторских партитур произведений композиторов разных стран и культурно-исторических эпох, а также научных трудов по вопросам теории и практики инструментовки, в статье раскрываются способы, особенности и тенденции применения инструментов семейства саксофонов в сочинениях для симфонического оркестра. Исследование проводилось путём изучения авторских партитур музыкальных произведений как прикладного, так и автономного направления. Для исследования использовались партитуры только тех произведений, в состав которьх авторами включалась одна или несколько партий саксофонов. В ходе изучения партитур отслеживались и выявлялись особенности, способы и тенденции трактовки саксофона в оркестре, характерные как для индивидуального авторского стиля, так и для стиля конкретной культурно-исторической эпохи. В результате проведённых исследований произошла систематизация сведений, посвящённых трактовке саксофона как оркестрового инструмента. Установлено распространение саксофона по странам и музыкальным жанрам. Изначально использовавшийся во французской преимущественно оперной музыке, к началу ХХ века саксофон вошёл в творческую практику композиторов других стран и направлений. Также в ходе исследования выявлены особенности, способы и тенденции трактовки саксофона как инструмента симфонического оркестра.
\end{abstract}

Ключевъе слова: Саксофон, трактовка саксофона, солирующий саксофон, оркестр, оркестровой элемент фактуры, произведения, симфонический оркестр, семейства саксофонов, композитор, французских композиторов.

Review: This article is devoted to one of the important problems of instrumentation which is not yet explored - the problem of saxophone interpretation. It also reflects the basic scientific result of the master's thesis under the same title. Based on the analysis of numerous works of composers living in different countries and different epochs as well as academic literature on the theory and practice of instrumentation, the author of the article discovers methods, peculiarities and trends in using a family of saxophone instruments in symphony orchestra compositions. The research was conducted based on the analysis of music scores of both applied and autonomous nature. The research covered only music pieces that had one or more saxophone parts. In the course of analyzing music scores, the author has traced back and defined peculiarities, methods and trends of orchestra saxophone interpretation typical for both the composer's individual style and the style of a particular culture-historical epoch. As a result of the research, the author has integrated data on interpretations of saxophone as an ochestra instrument. The author has also described how saxophone became famous in different countries and genres of music. Being used in French opera initially, by the beginning of the 2oth century saxophone became famous with the composers from other countries and genres of music. In the process of the research the author has also defined peculiarities, methods and trends in the interpretation of saxophone as a symphony orchestra instrument.

Keywords: French composers, family of saxophones, composer, symphony orchestra, works, element of the orchestral texture, orchestra, saxophone solo, saxophone interpretation, saxophone.

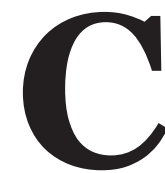

аксофон - духовой музыкальный инструмент - сконструирован в 1841 году бельгийским изобретателем А. Саксом (Адольф Антуан Жозеф Сакс - $1814-1894)$.

Для применения в симфоническом оркестре предназначались семейства инструментов в строях С и F, а в духовом оркестре - в строях В и Es.
Новизна инструмента заключалась в том, что в его конструкции сочетались черты как деревянных, так и медных духовых музыкальных инструментов. Подобно медным духовым, корпус был изготовлен из специального сплава, а способ звукоизвлечения и клапанный механизм заимствованы от деревянных. Созданный А.Саксом новый для той эпохи музыкаль- 
ный инструмент обладал полным, ярким и выразительным звуком, своеобразным тембром и технической подвижностью. Благодаря своим возможностям он привлёк внимание многих выдающихся композиторов и нашёл применение в оркестровых составах разных типов.

Статья посвящена анализу трактовки саксофона и систематизации способов его использования в симфоническом оркестре. Из огромного числа произведений, оставивших след в истории инструментальной музыки, рассматриваются лишь те из них, в которых авторы применяли инструменты этого семейства.

Вторая половина XIX века. Творческий поиск способов использования представителей семейства саксофонов был связан с творчеством французских композиторов. В первую очередь они обратились к инструментам низкой и средней тесситуры - саксофону-баcy (в строях С и В) и саксофону-баритону Es. Видимо, это отчасти было связано с тем, что симфонический (оперный) оркестр нуждался в духовом инструменте низкой тесситуры. К тому времени туба еще не стала постоянным инструментом симфонического оркестра.

Впервые применяет саксофон-бас СЖ. Кастнер в целом ряде номеров оперы «Последний царь Иудеи» (№11 «Мужской хор и № 12 «Ария», № 15 «Хор и ансамбль» и № 17 «Дуэт», № 18 «Трио» и № 19 «Финал»).

Показательным представляется №12 «Ария» (акт 2), где саксофону-басу на фоне сопровождения смычковых поручена мелодия, предваряющая вступление главной вокальной партии - партии Царя и ее дублировка. В результате партия главного героя приобретает наполненность и устойчивость. Кроме Ж.Кастнера инструмент такого строя использует Ж. Массне в опере «Король Лахорский» (1877), А. Маньяр в Первой симфонии (1891) отказывается от саксофона-баса $C$ и заменяет его саксофоном-басом в строе $B$.

Начиная с 6о-х годов XIX века, прослеживается практически всеобщий интерес композиторов к одухотворенному звучанию и технической подвижности саксофона-альта Es: например, кантата «Свадьба Прометея» (1867) и опера «Генрих VIII» (1883) К. СенСанса, оперы «Гамлет» (1868) и «Франческа да Римини» (1882) А.Тома, музыка к драме А. Доде «Арлезианка» (1872) Ж. Бизе и др.

Ж. Бизе применяет саксофон-альт Es почти во всех номерах музыки к драме А. Доде «Арлезианка» (кроме «Farandole» и «Adagietto»). В первой сюите «Арлезианка» этому инстру- менту поручаются четыре сольных эпизода. Лишь в одном из них мелодия изложена в октаву с кларнетом В, а остальные даются в чистом тембре саксофона-альта.

Разнообразно применяет солирующий саксофон-альт Es Ж. Массне. В связующем построении оперы «Иродиада» между вступлениями вокалистов этому инструменту поручена выразительная мелодия. Эмоциональное, технически подвижное solo саксофона построено на интонациях вокальной партии с учётом особенностей звучания регистров инструмента. В той же опере сольное пение сопровождается повторяющейся (по два такта) порученной саксофону-альту фигурацией, а в опере «Вертер» диалогом саксофона и кларнета на фоне выдержанных голосов (у струнных). В этом же произведении партия саксофона-альта Es, усиленная валторной, приобретает заметную смысловую самостоятельность и формообразующее значение: фраза имитируется и повторяется, а затем передается смычковым инструментам. Унисонные сочетания валторны с саксофоном и валторны с виолончелью являются связующим звеном для передачи имитирующейся фразы струнным (скрипкам).

Уже во второй половине XIX века прослеживается постепенный отказ от саксофонов в строях C и F и отчётливо проявляется тенденция к увеличению числа одновременно использующихся саксофонов. Если в 40-60-е годы композиторы ограничивались солирующим представителем семейства, то в последней четверти века и позднее нередко применялись три-четыре саксофона разных строев. Композиторы не ограничиваются применением солирующего саксофона в функции мелодии, перечень способов оркестрового письма постепенно расширяется.

Ж. Массне, например, с помощью тембра саксофона осуществляет плавный переход от смычковых к унисону смычковых и деревянных («тембровая модуляция»), а октавной дублировкой смычковых саксофонами (альтом и тенором) достигается необходимая насыщенность звучания ведущего элемента оркестровой ткани.

В музыке к драме А.Доде «Арлезианка» Ж.Бизе поручает саксофону-альту Es функцию в оркестровой ткани, которая в современном музыкознании называется мелодизированной педалью. Строящийся на выдержанных в размере такта звуках данный элемент выполняет роль «скрепа» оркестро- 
вой ткани (термин Б.Асафьева). Кроме того, выдержанные звуки наделяются движением подчёркиванием характерных гармонических звуков, а общее звучание обретает некоторые черты тембровой полифонии - «полифонии от тембра».

В этом же сочинении Ж. Бизе особая выразительность контрапунктирующего элемента достигается унисонным соединением саксофона-альта Es с виолончелью (верхняя струна). Общее звучание приобретает необходимое динамическое равновесие.

Сочинения французских композиторов второй половины XIX века содержат редкие примеры поиска способов использования саксофонов в гармоническом сопровождении. Так, в опере Ж. Массне «Иродиада» пар-

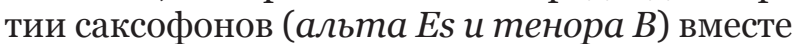
с натуральными валторнами и фаготами составляют самостоятельный слой оркестровой ткани - гармонически полную ритмическую фигурацию. Подобным образом Ж. Бизе применяет саксофон-альт Es в музыке к драме А. Доде «Арлезианка». В мощном оркестровом tutti саксофон-альm Es сочетается с медными инструментами, фаготами и частью смычковых в аккордовом сопровождении.

Многие композиторы применяют сочетания саксофонов с другими инструментами с целью изменения колорита, усиления общей звучности, выравнивания динамических соотношений между элементами оркестровой ткани. Так, например, в опере «Последний царь Иудеи» Ж. Кастнера (акт 2) сопоставимые по силе звучания и характеру партии саксофона-баса и фагота II вместе составляют подвижный (перемещзающийся) басовый голос. А. Маньяр во второй части первой симфонии соединяет саксофоны средней и низкой тесситуры - тенор $B$, баритон $E s$, бас $B$ - c кларнетами B. Благодаря такому сочетанию инструментов звучание медленной музыки аккордового склада приобретает черты, свойственные органу. В опере Ж. Массне «Иродиада» (акт 3) к унисону саксофона-альта Es и саксофона-тенора $B$ присоединяются корнет-а-пистон $B$ и труба $F$, а саксофонбас В дублирует басовый голос (у фаготов и тромбона III). Кроме того, Ж. Массне нередко трактует саксофон-альт Es как постоянный оркестровый инструмент деревянной групnы: два кларнета с саксофоном дублируют партии двух гобоев и английского рожка, саксофону и фаготу (в октаву) поручается самостоятельный элемент фактуры, сопоставля- ющийся как с вокальной партией и партией флейты, так и с басовым голосом.

Ряд примеров свидетельствует о поисках целесообразных способов использования саксофонов (-a) в tutti, где одной из важных задач композитора становится равновесие общей звучности (Ж. Бизе, сюита №2 из музыки к драме А. Доде «Арлезианка»; А. Маньяр, Первая симфония, часть II).

$\boldsymbol{X X ~ в е к . ~ Н а ~ р у б е ж е ~ X I X ~ и ~ X X ~ в . в . ~ п р о с л е ж и - ~}$ вается тенденция к более широкому использованию саксофона (-ов) не только в опере, но и в инструментальной оркестровой музыке. Интерес к саксофону проявили композиторы многих европейских стран и стран американского континента. Саксофоны в строях F и C встречаются лишь в «Домашней симфонии» Р. Штрауса и «Болеро» М. Равеля. Устойчивой тенденцией представляется стремление к расширению одновременно применяющихся представителей семейства до трех-пяти. Сформировавшиеся во второй половине XIX века способы использования инструментов семейства и их функции в оркестровой ткани не только нашли применение в музыке XX века, но и обогатились новыми.

Яркие примеры сольного использования саксофона - традиционного приема инструментовки в опере второй половины XIX века содержат произведения этого жанра в музыке первой половины XX века (П. Хиндемит, опера «Кардильяк» - саксофон-тенор B; 3. Кодаи, опера «Хари Янош» - саксофон-альт Es).

Ряд ярких примеров применения солирующего саксофона можно найти в творчестве С. Прокофьева. В одном из номеров кантаты «Александр Невский» («Въезд Александра в Псков») сопоставлениями деревянных инструментов, в окружении которых оказывается саксофон-альт, рисуется соответствующая образная картина. Подобный приём прослеживается и в балете «Ромео и Джульетта», где с деревянными сопоставляется саксофон-тенор. Затем этому инструменту от арфы передается гаммообразный пассаж, ставший своеобразным лейтмотивом Джульетты.

Сходный способ использования солирующего саксофона прослеживается и в «Симфонических танцах» С. Рахманинова. Имитационное развитие основного мотива подчеркивается тембром гобоя и кларнета, а затем на фоне секвенционного развития мотива (у кларнета) появляется протяжная мелодия у саксофона-альта, близкая по своему складу и образности русской народной песне. 
Выразительную мелодию поручает саксофону-альту Д. Шостакович в балете «Золотой век». Художественное впечатление достигается тесситурой мелодии и регистром использующегося инструмента, прозрачностью сопровождения, в котором сочетаются легкий бас pizzicato и «угрюмый» бас-кларнет, двухголосная гармоническая фигурация, а гаммообразное движение параллельными терциями (у валторн) не позволяет «пресытиться» (термин Н. Римского-Корсакова) тембром солирующего инструмента.

Колоритное, «внеземное» общее звучание достигается в одном из номеров балета «Деревянный принц» Б. Бартока применением саксофонов в функции мелодии (она поручена саксофону-альту Еs и саксофону-тенору В 흐 октаву). Мелодия отчётливо прослушивается на разноплановом фоне, включающем протянутые полифункциональные звуковые образования (у смычковых), функционально определённые аккорды (у арфы) и подвижную мелодическую фигурацию (у флейт).

В фактуре фрагмента из «Симфонии-реквиема» Б. Бриттена нет элементов, инертных в мелодическом движении. Партия саксофонаальта Еs наделена самостоятельным ритмом и содержит выдержанные звуки. (проверить по смыслу предложение) Выразительная сама по себе, она вместе с тем выполняет педализирующую роль - роль «скрепа» контрастных сопоставляющихся ансамблей инструментов. Подобную, но менее заметную при восприятии функцию обретает и партия смычкового альта.

В конце XIX и на протяжении XX века самыми применяемыми солирующими инструментами семейства саксофонов стали $a л ь m ~ E s$ и тенор $B$. Внимание композиторов привлекла не только ассоциирующаяся с человеческим голосом выразительность звука саксофона, но и его тембровое своеобразие. С участием саксофона многим композиторам удалось создать красочные образные картины, отражающие различные жизненные явления.

В «Домашней симфонии» Р. Штрауса саксофонам преимущественно поручается $\boldsymbol{\partial y}$ блировка различных элементов оркестровой ткани. Целью такой равнотесситурной дублировки становится усиление звучания или изменение окраски какого-либо элемента, а также достижение функционального равновесия элементов или выделение какого-либо из них.

Bo II акте оперы «Турандот» (1926) многоплановость оркестрового сопровождения унисона смешанного хора (перемещающаяся мно- гоголосная гармоническая фигурация у скрипок и арфы I, гармоническая основа у альтов, виолончелей, контрабаса и арфы II, заполнения имитационного характера у деревянных), видимо, побудила автора - Дж. Пуччини продублировать основную мелодию (октавный унисон смешанного хора) матовым тембром низких флейт и нежным звучанием двух саксофонов-альтов Es в их среднем регистре.

$\mathrm{B}$ «Танце саблями» из балета «Гаянэ» А. Хачатурян поручает саксофону-альту Еs выразительный мелодический элемент, который контрапунктирует по отношению к основной мелодии (скрипка I). Взаимодействие этих элементов оркестровой ткани зиждется на учете тембровых различий между инструментами (скрипка - саксофон). На этой же основе композитор допускает резкие диссонансы между основной мелодией и контрапунктом (м.2, б.7), что в свою очередь вносит немаловажные штрихи в образность самой музыки.

В известнейшем «Танце с саблями» из балета «Гаянэ» выразительную мелодию А.Хачатурян поручает унисону саксофонаальта и «нейтрального» по тембру смычкового альта. Подобный способ сочетания инструментов разных оркестровых групп широко применяется в симфонической музыке.

В сочинениях (Рапсодия в стиле блюз для ф-но с оркестром , Американец в Париже) Дж. Гершвина прослеживается формирование нового способа применения саксофонов. Суть этого способа состоит в том, что все инструменты семейства используются в единой функции - мелодии, сопровождении, заполнении и т.д. Кристаллизация такого способа становится наглядной в развитии второй темы: сначала унисон саксофонов соединяется с бас-кларнетом, фаготами, виолончелью и контрабасом, затем эта же мелодия излагается аккордово в три голоса.

На «рапсодия в стиле блюз для ф-но с оркестром» - в своеобразной четырехголосной фактуре (цифра 36) саксофонам поручаются верхние мелодизированные голоса (кроме баса), которые при вступлении солирующего фортепиано превращаются в гармонические. В последующем верхний голос обретает мелодическую самостоятельность, а затем три голоса объединяются ритмом.

Также у Дж. Гершвина можно найти немало ярких примеров равнотесситурной дублировки инструментов с целью усиления звучания, изменения тембра или достижения равновесия общей звучности. 
Редкое унисонное сочетание инструментов (гобой - саксофон-альт) содержит «Рапсодия в стиле блюз для ф-но с оркестром» Дж. Гершвина. Особенность такого сочетания состоит в том, что столь характерные тембры не сливаются и поэтому воспринимаются как бы порознь. Видимо, такой художественный результат автору был желателен.

Ещё более необъиное соединение инструментов применяется для первого изложения основной темы той же «Рапсодии в стиле блюз для ф-но с оркестром» Дж. Гершвина. Мелодия поручается унисону саксофона-тенора, валторны и бас-кларнета, а во втором такте (как бы с опозданием на такт) к ним присоединяется тромбон. Казалось бы, что на прозрачном фоне выдержанного мажорного трезвучия у смычковых и деревянных (Es-dur) мелодия убедительно прозвучала бы в исполнении каждого из соединяемых инструментов. Объяснить намерения автора можно лишь формирующимися во время написания рапсодии исполнительскими традициями джазовых ансамблей - сначала тему играют все вместе, а затем поочередно выступают с импровизациями.

В сочинении "Американец в Париже» Дж. Гершвин идет еще дальше: саксофонам (альт Es, тенор B, баритон Es) здесь поручается самостоятельный элемент оркестровой ткани - аккордово изложенный контрапункт. Композитор находит способ использования саксофонов в единой функции, которая является гармоническим сопровождением.
В сочинениях Дж.Гершвина, таким образом, отчетливо проявился определяющий признак, характеризующий новый способ применения саксофонов в мелодии и гармонии, иных элементах оркестровой ткани, - функциональное единство используемых представителей семейства.

Необычные унисонные сочетания саксофона-альта с различными оркестровыми инструментами применяет Л. Бернстайн в мюзикле «Вестсайдская история», среди которых вибрафон, вибрафон и гитара, валторны, трубы.

Несмотря на значительный интерес композиторов к разнообразным свойствам звука, художественным и техническим возможностям семейства саксофонов, его представители не стали постоянными инструментами симфонического оркестра. Одной из возможных причин этого мог оказаться зародившийся на рубеже веков и бурно развивавшийся в $\mathrm{XX}$ веке джазово-эстрадный оркестр, своеобразной «эмблемой» которого стал саксофон.

Другая же причина вытекает из наполненного философским содержанием суждения А.Карса - автора признанного труда «История оркестровки». Говоря о проявившейся на рубеже веков тенденции к расширению состава симфонического оркестра, он утверждает, что «... увеличение силы тембров, уже и раньше представленных в оркестре, должно встретить затруднения; ... если кто-нибудь хочет постоянно прибавлять новые инструменты к оркестру, то он должен в то же время изобрести новый способ приведения воздуха в колебание».

\section{Библиография:}

1. Берлиоз Г. Большой трактат о современной инструментовке и оркестровке в двух томах. М.: Музыка, 1972. Т. 2. С. 494.

2. Глинка М. Заметки об инструментовке // М.И. Глинка. Полное собрание сочинений. Литературные произведения и переписка в 2 томах (комплект из 3 книг). Т. 1. М.: Музыка, 1973. С. 179-181.

3. Геварт Ф. Руководство к инструментовке // П.И. Чайковский. Полное собрание сочинений. Т. ІІІ-б / Том подготовлен Вл. Протопоповым. М.: Государственное Музыкальное Издательство, 1961. С. 347-349.

4. Карс А. История оркестровки. М.: Музыка, 1990. С. 296.

\section{References (transliterated):}

1. Berlioz G. Bol'shoi traktat o sovremennoi instrumentovke i orkestrovke v dvukh tomakh. M.: Muzyka, 1972. T. 2. S. 494.

2. Glinka M. Zametki ob instrumentovke // M.I. Glinka. Polnoe sobranie sochinenii. Literaturnye proizvedeniya i perepiska v 2 tomakh (komplekt iz 3 knig). T. 1. M.: Muzyka, 1973. S. 179-181.

3. Gevart F. Rukovodstvo k instrumentovke // P.I. Chaikovskii. Polnoe sobranie sochinenii. T. III-b / Tom podgotovlen Vl. Protopopovym. M.: Gosudarstvennoe Muzykal'noe Izdatel'stvo, 1961. S. 347-349.

4. Kars A. Istoriya orkestrovki. M.: Muzyka, 1990. C. 296. 